\title{
Improved quality of life and body satisfaction in response to activity-based therapy in adults with spinal cord injury
}

\author{
Todd A. Astorino', Eric T. Harness² \\ 1Department of Kinesiology, California State University, San Marcos, CA 92096-0001, USA. \\ ${ }^{2}$ Neuro Ex, Oceanside, CA, USA.
}

Correspondence to: Prof. Todd A. Astorino, Department of Kinesiology, California State University, San Marcos, 333. S. Twin Oaks Valley Road, UNIV 320, San Marcos, CA 92096-0001, USA. E-mail: astorino@csusm.edu

How to cite this article: Astorino TA, Harness ET. Improved quality of life and body satisfaction in response to activity-based therapy in adults with spinal cord injury. Neuroimmuno/ Neuroinflammation 2020;7:40-50.

http://dx.doi.org/10.20517/2347-8659.2019.11

Received: 28 Sep 2019 First Decision: 16 Dec 2019 Revised: 20 Feb 2020 Accepted: 25 Feb 2020 Published: 21 Mar 2020

Science Editor: Swapan Ray Copy Editor: Jing-Wen Zhang Production Editor: Tian Zhang

\begin{abstract}
Aim: The decline in ambulation characteristic of spinal cord injury ( $\mathrm{SCl}$ ) dramatically modifies quality of life and body composition. To examine changes in quality of life, body satisfaction, and body composition in response to 6 months of activity-based therapy in individuals with spinal cord injury $(\mathrm{SCl})$.
\end{abstract}

Methods: Men and women with complete or incomplete $\mathrm{SCl}(12$ with tetraplegia and 13 with paraplegia; mean age and duration of injury of $35.8 \pm 12.9$ years and $3.8 \pm 5.5$ years, respectively) completed 6 months of activity-based therapy consisting of load bearing, locomotor training, whole-body resistance training, functional electrical stimulation, and assisted/unassisted walking for $8.5 \pm 4.3 \mathrm{~h} /$ week. At baseline and at 3 and 6 months of training, body satisfaction, perceived quality of life, depression, and bodily pain were assessed using various questionnaires, and whole-body and regional fat mass and fat-free mass were determined with dual-energy X-ray absorptiometry. One-way analysis of variance with repeated measures was used to examine changes in outcome measures during the study.

Results: Measures of body satisfaction (+23\%) and quality of life $(+8 \%)$ were improved $(P<0.05)$ in response to training, yet no change in depression or pain was demonstrated $(P>0.05)$. Percent body fat increased $(P=0.02)$, yet no change $(P>0.05)$ was seen in whole-body or regional fat free mass.

Conclusion: Data suggest that chronic high-volume activity-based therapy enhances various indices of quality of life in men and women with $\mathrm{SCl}$, but may be an ineffective approach to reduce fat deposition and increase muscle mass after $\mathrm{SCl}$.

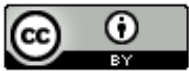

(C) The Author(s) 2020. Open Access This article is licensed under a Creative Commons Attribution 4.0 International License (https://creativecommons.org/licenses/by/4.0/), which permits unrestricted use, sharing, adaptation, distribution and reproduction in any medium or format, for any purpose, even commercially, as long as you give appropriate credit to the original author(s) and the source, provide a link to the Creative Commons license, and indicate if changes were made.

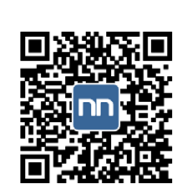


Keywords: Body satisfaction, depression, rehabilitation, fat free mass, paralysis

\section{INTRODUCTION}

The paralysis associated with spinal cord injury (SCI) compromises locomotion and, in turn, diminishes physical function and leads to various secondary complications including obesity and insulin resistance ${ }^{[1]}$. Above and beyond the physical effects of SCI is the onset of various psychological issues that may affect perceived quality of life (PQOL), which encompasses aspects of happiness, health, quality of family relationships, and financial and physical independence ${ }^{[2]}$. In fact, in men and women with SCI, wellbeing is negatively associated with self-reported overweight status and onset of secondary complications ${ }^{[3]}$, which emphasizes the need to also consider participants' psychological state during rehabilitation. Data on persons with SCI demonstrate that aerobic and resistance exercise training improves PQOL compared to non-exercising controls ${ }^{[4]}$, although PQOL was reduced after a decline in physical activity three months later $^{[5]}$. Incidence of pain is also common in SCI, as, in a survey of 200 individuals, $25 \%$ had more severe pain and $44 \%$ reported that it interfered with daily activities ${ }^{[6]}$. Moreover, pain decreases quality of life and serves as a barrier to regular exercise participation in $\mathrm{SCI}^{[6]}$. In addition, more pain is consequent with greater incidence of depression ${ }^{[7]}$, which is widely studied in persons with $\mathrm{SCI}^{[8]}$, and incidence of substantial pain may negatively influence participation in rehabilitation. Moreover, depression is associated with body image disturbances and body dissatisfaction, which are common in persons with disability such as $\mathrm{SCI}^{[9]}$. With exception of one study showing positive effects on quality of life ${ }^{[4]}$, little is known about efficacy of exercise training to modify quality of life and body satisfaction in SCI.

As stated above, quality of life is associated with body composition that is severely altered after SCI. For example, Moore et al. ${ }^{[10]}$ reported that persons with chronic incomplete or complete SCI have $14 \%-32 \%$ lower muscle cross sectional area in the calf than controls. Moreover, lower extremity fat deposition is up to fourfold higher in SCI versus able-bodied persons ${ }^{[11]}$, and there is a loss of lean body mass in the trunk and $\operatorname{arms}^{[12]}$ that reduces physical function and capacity for day-to-day activities including wheelchair ambulation, all leading to altered quality of life. In addition, visceral adipose tissue is typically higher ${ }^{[13]}$, which increases the risk of cardiovascular disease and diabetes ${ }^{[14,15]}$. Chronic aerobic and resistance exercise training can modify body composition in SCI, but the majority of data showing positive effects are from studies employing lower extremity functional electrical stimulation (FES) using leg cycling ${ }^{[16]}$, resistance training ${ }^{[17]}$, or subtetanic contractions ${ }^{[18,19]}$ that are often inaccessible for people with SCI. Recent studies show no change in body composition in response to completion of chronic upper-body resistance training $^{[13]}$ or arm ergometry ${ }^{[20]}$, two widely-used exercise modes in this population. Consequently, a recent review ${ }^{[21]}$ concluded that there is insufficient evidence to support exercise training to modify body composition in SCI.

One rehabilitation modality frequently used in this population is activity-based therapy (ABT), which targets activation of the neuromuscular system below the injury level, with a goal of retraining the nervous system to recover a specific motor task such as locomotion ${ }^{[22]}$. Institution of ABT using modalities including load bearing, locomotor training, resistance training, and/or FES typically targets the paralyzed or partially paralyzed muscles and may also aid in prevention or treatment of various secondary health complications seen after SCI. In a randomized controlled trial, Jones et al. ${ }^{[23]}$ showed that ABT significantly improved walking-related outcomes in persons with incomplete SCI. Nevertheless, exercise training such as ABT requiring voluntary contractions may have a lesser ability to modify body composition ${ }^{[24,25]}$, although this is not universal ${ }^{[26]}$. Therefore, it is unclear if body composition can be modified with voluntary exercise in SCI such as $\mathrm{ABT}$, and if any change in body composition is consequent with a change in quality of life. If ABT does not elicit changes in body composition, alternative exercise modalities may need to be implemented to improve this outcome in this population. 
The current study examined effects of chronic ABT on perceived quality of life, pain, body satisfaction, and body composition in persons with SCI, which are related to subjective well being. Data from a recent review $^{[27]}$ of four studies containing 139 participants indicated no effect of ABT on quality of life, yet most included studies were of low quality. Data from Dolbow et al. ${ }^{[28]}$, Sharif et al. ${ }^{[29]}$, and Sadowsky et al. ${ }^{[30]}$ show greater quality of life after FES training, yet it is unknown if similar results can occur with multi-modal ABT. It was hypothesized that ABT would improve measures of quality of life and body satisfaction, but not pain, fat free mass (FFM), or fat mass (FM) in men and women with SCI. Resultant data can be used towards identifying effective rehabilitation strategies targeting these outcomes, which are associated with physical and psychological function and overall well-being of persons with SCI.

\section{METHODS}

\section{Design: this study was a within-subjects longitudinal project}

Participants initiated 6 months of exercise training, which was continuously supervised by personnel trained in SCI rehabilitation at a local ABT facility. During a single session at baseline and at three and six months, a survey was completed to assess variables including body satisfaction, pain, depression, and quality of life, and participants underwent dual-energy X-ray absorptiometry (DXA) scans to determine whole body and regional body composition. This session was overseen by the primary investigator. In addition, a four-day food log was completed. Assessments were performed a minimum of $18 \mathrm{~h}$ after their last training session. Time of day was maintained across all trials within participants. Compliance to training was monitored each day by staff at the facility.

\section{Participants}

Twenty-nine men and women with SCI were initially recruited and subsequently initiated this study; they were recruited by word-of-mouth. They comprised a convenience sample of patients completing ABT at a local rehabilitation facility. Eighteen individuals were identified as Caucasian, six as Hispanic, three as Middle Eastern, and two as African-American. Initially, participants' health history was examined with a brief survey to ensure they met these inclusion criteria: complete or incomplete SCI, injury level lower than $\mathrm{C} 2$, non-ventilator dependent, and physician's permission to engage in an intense exercise program. Prospective participants were excluded if they completed regular ABT (locomotor training, assisted/unassisted walking, etc.) in the preceding 12 months or were unwilling to abstain from additional exercise other than wheelchair ambulation outside the study; lacked the physical function or had excess pain to complete training; were taking medications altering body composition or mental status (such as testosterone, antidepressants, and/or diabetic and/or cardiovascular drugs) other than calcium or vitamin D supplements; had medical conditions besides paralysis that alter body composition, such as diabetes or hyperthyroidism; were peri- or post-menopausal; or suffered an acute infection. Participants provided informed consent to participate in the study, which was approved by the University Institutional Review Board and was conducted in accordance with the Declaration of Helsinki.

\section{Assessment of quality of life}

Using an interview format, the primary investigator read each item to the participant and recorded his/ her response, as not all participants could use pen and paper. Initially, the 10-item body satisfaction survey $(B S S)^{[31]}$ was completed, with scores ranging from -3 (very dissatisfied) to +3 (very satisfied). This survey has a range of scores from -30 to +30 and included questions pertaining to physical function (seven items) and appearance (BSS-A) (three items), which were scored separately. Next, participants were asked "how much bodily pain have you had in the last four weeks" and "how much did pain interfere with your normal work/day-to-day activities", which were scored from 1 (none) to 6 (very severe). These were taken from the Short Form-36 survey (SF-36) scale ${ }^{[32]}$ and have been previously utilized in $\mathrm{SCI}^{[2]}$. The 11-item PQOL scale ${ }^{[2]}$ containing four additional items related to quality of life in $\mathrm{SCI}^{[33]}$ was then completed, in which participants were asked their degree of satisfaction on a scale of 0-100. 
Subsequently, we asked participants questions regarding the severity of onset of secondary complications commonly seen in SCI including spasms, joint stiffness, constipation, urinary tract infection, pain, etc., using the following scale previously developed in this population ${ }^{[34]}:$ (1) "I don't have this problem"; (2) "Problem is not at all bothersome"; (3) "Problem is slightly bothersome"; (4) "Problem is moderately bothersome"; and (5) "Problem is greatly bothersome".

Lastly, the Center for Epidemiological Studies Depression scale ${ }^{[35]}$ was completed. Participants were asked to rank on a 0 (rarely or none of the time) to 3 (most or all of the time) scale how they felt about each of 20 items during the last week. The overall score was the sum of all 20 items for a total possible score equal to 60. This survey is reliable and valid in persons with $\mathrm{SCI}^{[36]}$.

\section{Assessment of body composition}

Participants arrived at the laboratory after an overnight fast $(>10 \mathrm{~h})$ wearing exercise attire without metal. Initially, the participant was placed on the dual-energy X-ray absorptiometer (DXA software version 13.5, Lunar Prodigy Advance, GE Healthcare, Madison, WI, USA) for a few minutes to minimize muscle spasm. They were instructed to remain motionless and not talk during the scan, which was used to estimate whole-body and regional (arm, trunk, and legs) FM and FFM. Body weight (in kg) was calculated from the summation of FM, FFM, and bone mineral content. Body composition changes during the study were expressed in absolute units $(\mathrm{kg})$. Analyses were performed by the same technician who followed standard quality control procedures developed by the manufacturer. Intraclass correlation coefficients and coefficients of variation for whole-body and regional determinations of FM and FFM obtained in five individuals with SCI measured three months apart were equal to 0.98 and 0.99 and $0.7 \%$ and $0.8 \%$, respectively. In addition, waist circumference was obtained in duplicate in the supine position according to standardized procedures $^{[37]}$.

\section{Assessment of dietary intake}

Participants completed a four-day food log (including two weekend days) at baseline and at three and six months. They were encouraged to actively report all food and drink ingested (including supplements) each day with specific instructions to describe method of preparation, portion sizes, and brands where applicable. This information was reviewed during each visit and used to determine total caloric intake as well as fat, carbohydrate (CHO), and protein intake (in g) using a commercially-available website (http:// ndb.nal.usda.gov/ndb/foods/list). They were asked to maintain their dietary practices during the study.

\section{Intervention}

Participants performed 2-3 h sessions of supervised ABT targeting the lower extremities (80\% for those with tetraplegia and $100 \%$ for paraplegia) a minimum of two days/week to a maximum of five days/week. Activitybased therapy was shown to enhance motor gains in persons with chronic $\mathrm{SCI}^{[38]}$. This regimen elicits energy expenditure between 5 and $8 \mathrm{~mL} / \mathrm{kg} / \mathrm{min}^{[39]}$, which is similar to circuit training and FES leg cycling ${ }^{[40,41]}$ yet lower than arm ergometry, wheelchair ambulation ${ }^{[40]}$, or exoskeleton-assisted walking ${ }^{[42]}$. ABT as performed in the current study consisted of these modalities as previously described ${ }^{[38,43]}: 1.5-2.0 \mathrm{~h} /$ week of active assistive exercise, $1.5 \mathrm{~h} /$ week of upper/lower body and core resistance training, $1 \mathrm{~h} /$ week of load bearing, $30 \mathrm{~min} /$ week of arm/cycle ergometry, 1.0-2.0 h/week of gait training including assisted and unassisted walking as well as body weight-supported mechanized elliptical training, 10-30 min/week of vibration training, and $30 \mathrm{~min} /$ week of FES of the quadriceps, gluteals, and hamstrings. Training was individualized for each client based on their baseline function, and progression was instituted daily based on participant tolerance to training and level of adaptation. During the study, time performing active assistive exercises and passive gait training generally decreased while time performing resistance training and active gait training increased. Training volume differed across participants as rehabilitation costs were paid out-of-pocket. 
Table 1. Physical characteristics of participants completing six months of activity-based therapy $(n=25)$

\begin{tabular}{lll}
\hline Parameter & Mean (SD) & Range \\
\hline Age (year) & $35.8 \pm 12.9$ & $18-59$ \\
Height (cm) & $178.7 \pm 7.1$ & $158-188$ \\
Mass (kg) & $77.0 \pm 13.1$ & $53.7-101.0$ \\
DOI (year) & $3.8 \pm 5.5$ & $0.2-10.0$ \\
Complete/incomplete & $9 / 16$ & $\mathrm{NA}$ \\
Tetraplegia/paraplegia & $12 / 13$ & $\mathrm{NA}$ \\
Injury level & $\mathrm{NA}$ & $\mathrm{C} 5-\mathrm{L} 1$ \\
Gender (male/female) & $22 / 3$ & \\
\hline
\end{tabular}

SD: standard deviation; cm: centimeters; kg, kilograms; DOI: duration of injury; NA: non-applicable

\section{Data analysis}

Data are reported as mean \pm standard deviation (SD) and were analyzed using SPSS Version 20.0 (Chicago, IL). Initially, normality of all variables was examined. Two-way (one within-subjects factor representing training (zero, three, and six months) and one between-subjects factor including injury completeness, severity, and duration of injury as well as training volume) analysis of variance with repeated measures was used to examine changes in all variables in response to training. Overall, data were combined across participants as there were few baseline differences or group $\times$ time interactions in most outcome measures when variables including duration of injury, injury completeness, or injury severity were considered. The Greenhouse-Geisser correction was used to account for the sphericity assumption. If a significant $F$ ratio was obtained, Tukey's post hoc test was used to identify differences between means. Partial eta-squared $\left(\eta_{\mathrm{p}}^{2}\right)$ was used as an estimate of effect size. Multiple regression was used to examine predictors of the change in body satisfaction and quality of life. Statistical significance was set at $P<0.05$.

\section{Data availability statement}

De-identified data from this study are available upon request.

\section{RESULTS}

One woman and three men dropped out after one month $(n=2)$ and five months $(n=2)$ due to injury unrelated to training and moving out of the area. Our results are from 22 men and 3 women who completed six months of $\mathrm{ABT}$ and were assessed at baseline and at three and six months of training. Fourteen participants were within one year post-SCI. Participants' injury level included C5-C6 $(n=7)$, C4 $(n=3), \mathrm{T} 3-\mathrm{T} 4(n=5), \mathrm{T} 6-\mathrm{T} 10(n=4), \mathrm{T} 11(n=1), \mathrm{T} 12(n=4)$, and L1 $(n=1)$. Participant characteristics are demonstrated in Table 1. Adherence to training was equal to $100 \%$. Training volume across participants ranged 4-17 h/week, with a mean value equal to $8.5 \pm 4.3 \mathrm{~h} /$ week. However, when training volume was used as a between subjects factor in all analyses, there was no effect $(P>0.05)$ of this factor on our outcomes. Where applicable, we separated participants by low $(<8 \mathrm{~h} /$ week, $n=14)$ and high volume of ABT $(>8 \mathrm{~h} /$ week, $n=11)$.

\section{Change in body satisfaction and pain in response to $A B T$}

The results show a main effect of training on BSS $\left(P=0.03, \eta_{p}^{2}=0.13\right)$ in that it increased during the study. Post hoc analyses showed that the six-month score was higher than at baseline by 0.60 (Table $2, \mathrm{~d}=1.0)$. When injury completeness was used as a between-subjects factor, there was a main effect of training $(P=0.04$, $\left.\eta_{p}^{2}=0.13\right)$ and training $\times$ completeness interaction $\left(P=0.02, \eta_{p}^{2}=0.15\right)$. Post hoc analyses showed that BSS increased from baseline to six months of training in persons with incomplete SCI $(-0.87 \pm 1.30 v s$. $+0.38 \pm 1.40, \mathrm{~d}=1.5)$ but not in complete SCI $(0.68 \pm 1.63 v s .0 .78 \pm 1.32, \mathrm{~d}=0.1)$. For BSS-A, there was a main effect of training $\left(P=0.01, \eta_{\mathrm{p}}^{2}=0.17\right)$ and post hoc analyses showed that three- $(+0.8, \mathrm{~d}=0.8)$ and six-month values $(+0.9, \mathrm{~d}=0.8)$ were greater than baseline. BSS-A was higher in persons with paraplegia versus tetraplegia $\left(P=0.02, \eta_{\mathrm{p}}^{2}=0.19\right)$, although no training $\times$ group interactions were found across injury duration, severity, or completeness. Pain was unchanged $(P=0.67)$ in response to training. 
Table 2. Changes in indices of quality of life (mean \pm SD) in response to six months of activity-based therapy in persons with $\mathrm{SCl}$

\begin{tabular}{llll}
\hline Parameter & Zero months & Three months & Six months \\
\hline BSS & $-0.36 \pm 1.62$ & $0.22 \pm 1.48$ & $0.44 \pm 1.38^{\star}$ \\
BSS-A & $-0.82 \pm 1.59$ & $-0.01 \pm 1.80^{\star}$ & $0.04 \pm 1.54^{\star}$ \\
PQOL & $60.4 \pm 18.2$ & $59.7 \pm 19.8$ & $64.5 \pm 20.6 \mathrm{a}$ \\
CESD & $21.3 \pm 6.9$ & $20.8 \pm 5.7$ & $19.7 \pm 5.3$ \\
Pain & $4.5 \pm 1.3$ & $4.4 \pm 1.4$ & $4.5 \pm 1.3$ \\
Don't have secondary complications (\%) & $48.1 \pm 16.8$ & $41.9 \pm 21.7$ & $43.0 \pm 18.6$ \\
Bothersome secondary complications (\%) & $7.2 \pm 9.9$ & $4.4 \pm 7.4$ & $3.6 \pm 5.6$ \\
\hline
\end{tabular}

BSS: body satisfaction survey; BSS-A: body satisfaction survey - appearance; PQOL: perceived quality of life; CESD: Center for Epidemiological Studies depression scale; SCl: spinal cord injury; SD: standard deviation. ${ }^{\star} P<0.05$ vs. zero-month value; ${ }^{a} P<0.05$ vS. three-month value

\section{Change in perceived quality of life and depression in response to ABT}

Perceived quality of life differed with training $\left(P=0.04, \eta_{p}^{2}=0.11\right)$ and post hoc analyses showed that the six-month value was higher than at three months [Table 2] by approximately five units $(d=0.8)$. Change in PQOL from baseline to six months was higher in persons with acute $(+7.6 \pm 12.9)$ or incomplete injury $(+7.5 \pm 11.2)$ compared to chronic $(+0.7 \pm 7.4)$ or complete injury $(+0.9 \pm 11.6)$, although it failed to reach significance $(P=0.10)$. The results show no change in depression $(P=0.30)$ from baseline to six months and there were no effects of injury level, completeness, or volume of physical activity on this response.

\section{Regression data}

Various two-predictor models were developed to identify the best predictors of change in PQOL and body satisfaction in response to training. A model $(r=0.63, F=7.05, P=0.004)$ consisting of age $(r=-0.41, P=0.02)$ and change in pain $(r=-0.48, P=0.007)$ explained $39 \%$ of the variance in change in PQOL. Although percent body fat was correlated with change in BSS $(r=0.33, P=0.049)$, no significant models were found. For change in BSS-A, a significant model $(r=0.504, F=4.08, P=0.03)$ consisted of body fat $(r=0.36, P=0.03)$ and baseline pain $(r=0.27, P=0.08)$.

\section{Change in body composition in response to $A B T$}

Body composition results are revealed in Table 3. Body mass $(P=0.30)$ did not change but \%BF (body fat) increased $\left(P=0.02, \eta_{\mathrm{p}}^{2}=0.17\right)$ from baseline to six months by $1 \%$. Whole-body FFM did not change across time $(P=0.11)$, but there was a training $\times$ group interaction in that it declined by approximately $2 \mathrm{~kg}$ in individuals with complete SCI $(n=9,50.8 \pm 7.9 \mathrm{~kg}$ to $48.7 \pm 7.0 \mathrm{~kg})$, but did not change in participants with incomplete injury $(n=16,47.7 \pm 7.4 \mathrm{~kg}$ to $47.5 \pm 7.5 \mathrm{~kg})$. Leg FFM $(P=0.88)$, leg \%BF $(P=0.08)$, and waist circumference $(P=0.80)$ were unchanged during the study. There was a tendency for trunk FFM to decline during the study $(P=0.06)$. Trunk \%BF increased $(P=0.03)$, and post hoc analyses showed that three- and six-month values were higher by $1.2 \%-1.3 \%$ than at baseline. There were no differences in arm FFM ( $P$ $=0.20)$ or $\% \mathrm{BF}(P=0.13)$ during the study. Arm FFM was higher $(P=0.003)$ in persons with paraplegia versus tetraplegia. From baseline to six months of training, whole-body \%BF declined by more than the coefficient of variation of the measure in $24 \%$ of participants, and $32 \%$ of participants showed increases in whole-body FFM.

\section{Change in dietary intake}

Data revealed that total energy intake declined from baseline $(1769.1 \pm 349.3 \mathrm{kcal}, 1650.3 \pm 410.4 \mathrm{kcal}$, and $1660.9 \pm 366.9 \mathrm{kcal}, P=0.03)$, whereas fat $(64.9 \pm 15.0 \mathrm{~g}, 59.7 \pm 15.8 \mathrm{~g}$, and $60.6 \pm 16.2 \mathrm{~g}, P=0.20)$, CHO $(211.6 \pm 53.0 \mathrm{~g}, 197.2 \pm 53.6 \mathrm{~g}$, and $201.0 \pm 54.5 \mathrm{~g}, P=0.17)$, and protein intake $(78.3 \pm 21.1 \mathrm{~g}, 80.6 \pm 26.0 \mathrm{~g}$, and $74.2 \pm 28.5 \mathrm{~g}, P=0.27)$ were unaltered. 
Table 3. Changes in body weight and body composition (mean \pm SD) in response to six months of activity-based therapy in persons with $\mathrm{SCl}$

\begin{tabular}{llcc}
\hline Parameter & Zero months & Three months & Six months \\
\hline Mass (kg) & $76.3 \pm 13.2$ & $77.1 \pm 13.1$ & $77.0 \pm 13.4$ \\
Whole-body FFM (kg) & $48.8 \pm 7.9$ & $48.6 \pm 7.4$ & $47.9 \pm 7.2$ \\
\%BF & $32.7 \pm 12.2$ & $33.6 \pm 11.7^{\star}$ & $33.8 \pm 11.2^{\star}$ \\
WC (cm) & $91.0 \pm 13.0$ & $90.7 \pm 14.6$ & $90.1 \pm 13.4$ \\
Leg FFM (kg) & $14.3 \pm 3.0$ & $14.3 \pm 3.1$ & $14.3 \pm 2.9$ \\
Leg \%BF & $36.4 \pm 11.9$ & $37.3 \pm 11.3$ & $37.5 \pm 10.8$ \\
Trunk FFM (kg) & $24.2 \pm 3.6$ & $23.9 \pm 3.3$ & $23.6 \pm 3.4$ \\
Trunk \%BF & $33.4 \pm 13.5$ & $34.6 \pm 13.4^{\star}$ & $34.7 \pm 12.7^{\star}$ \\
Arm FFM (kg) & $6.1 \pm 1.9$ & $6.3 \pm 1.8$ & $6.3 \pm 1.9$ \\
Arm \%BF & $27.1 \pm 13.7$ & $27.6 \pm 14.3$ & $28.6 \pm 13.2$ \\
\hline
\end{tabular}

kg: kilograms; FFM: fat-free mass; BF: body fat; WC: waist circumference; SD: standard deviation; SCl: spinal cord injury. ${ }^{\star} P<0.05$ vS. baseline

\section{DISCUSSION}

Despite no significant improvements in FFM or FM, bodily pain, or depression, individuals with SCI undergoing six months of ABT revealed small but significant increases in PQOL and body satisfaction. Although our data cannot explain what led to this improved quality of life, previous reports indicate that exercise improves sense of control and mastery that people have regarding their physical function ${ }^{[44]}$. Due to the potential link between quality of life and exercise participation in $\mathrm{SCI}^{[3]}$, structuring exercise programs targeting these outcomes may help promote exercise adherence in this population.

Supporting our findings, improved PQOL has been reported in response to exercise training in SCI. In men and women at least one year post-SCI ${ }^{[4]}$, nine months of resistance training and arm cycling improved PQOL, which was coincident with reduced pain, depression, and greater muscle strength and arm cycling performance that, in turn, might elicit an improved mental health profile. Similarly, improved PQOL occurred in patients undergoing 12 weeks of FES ambulation training despite no change in depression ${ }^{[29]}$. Nevertheless, in persons with complete SCI, 18 months of incorporation of ABT into daily activities had no effect on functional independence or quality of life (measured with the Short Form-36) ${ }^{[45]}$. Jones et al. ${ }^{[23]}$ reported no change in quality of life despite increased walking speed in men and women with incomplete SCI undergoing six months of ABT. Potential explanations for no change in PQOL can be due to a ceiling effect or inclusion of participants with varying injury duration, as persons with chronic SCI may come to terms with their injury and may believe that it no longer alters their quality of life. Alternatively, we had many individuals within one year of injury who likely struggle with the challenges of acute SCI and report a low quality of life. Our ABT regime was also held in a facility providing social interactions to clients that also may enhance PQOL.

In 695 men and women with $\mathrm{SCI}^{[3]}$, a greater incidence of pain and depression and lower life satisfaction was found in overweight versus normal weight individuals, likely due to greater difficulty in completing activities of daily living. Previous studies also suggest that body satisfaction may be higher ${ }^{[46]}$ or lower $^{[47]}$ in persons with greater physical activity. Our body satisfaction values are lower than those reported in men approximately 15 years post-SCI ${ }^{[48]}$, likely due to their more recent injury status and higher levels of body fat. Similar to our findings, 10 weeks of exercise training in a heterogeneous group of men and women with SCI improved functional and appearance-related body satisfaction ${ }^{[49]}$. Overall, various modes of exercise including ABT have the potential to improve body satisfaction in persons with SCI. Because of our small sample and lack of a control group, our results showing enhanced body satisfaction are preliminary and require further study to confirm. 
Our results show no change in bodily pain, which may be due to the fact that many participants reported no or minimal pain at baseline. This finding opposes previous results; for example, in individuals with chronic SCI, 12 weeks of FES-ambulation training reduced bodily pain ${ }^{[29]}$, similar to findings seen in response to nine months of resistance/aerobic training ${ }^{[4]}$. In persons with paraplegia, four months of circuit training reduced shoulder pain, which was consequent with increased total body strength ${ }^{[50]}$. In addition, a single bout of locomotor training may reduce pain perception in persons with incomplete $\mathrm{SCI}^{[51]}$. However, findings from one study ${ }^{[5]}$ demonstrated no change in pain after nine months of aerobic and resistance training, which was seen as a positive response considering that non-exercising controls showed greater pain. Baseline pain was also associated with change in BSS-A, and our participants' change in pain was a significant predictor of change in PQOL, which supports previous findings ${ }^{[3]}$. As pain is related to exercise adherence ${ }^{[3,52]}$, mobility ${ }^{[53]}$, and onset of depressive symptoms ${ }^{[54]}$, rehabilitation and fitness professionals should consider this outcome when treating persons with SCI who have elevated pain.

In the present study, we used the Center for Epidemiological Studies Depression scale to assess potential changes in depression in response to ABT. It is evident ${ }^{[55]}$ that scores above 16 may identify individuals at risk for clinical depression. Although our participants' scores declined by two units from baseline to six months, this change was not significant. Our heterogeneous sample may have been too small to detect changes in depression considering that greater than 40 participants may be needed for adequate statistical power ${ }^{[5]}$. Moreover, examination of change in depression with between-subjects factors equal to injury severity, duration, completeness, and volume of training did not reveal any differences between groups. In another study ${ }^{[4]}$, fewer depressive symptoms were noted after nine months of exercise training in individuals with SCI compared to non-exercising controls, although their baseline score did not indicate clinical depression and, in addition, the value did not increase from pre- to post-training.

Our data do not support the efficacy of ABT to improve body composition measured via DXA, as whole body and regional \%BF increased and there was no change in FFM [Table 3]. However, the observed increase in $\% \mathrm{BF}$ is minimal and may not be clinically meaningful in regards to enhancing risk of comorbidities associated with SCI. In contrast, decreased FM and increased FFM occurred ${ }^{[17,19]}$ when long-term FES is performed by persons with acute as well as chronic paraplegia and tetraplegia. There are a few explanations for the lack of change in body composition in response to ABT. First, our ABT regime required more core and upper-body resistance training than exposure to FES, which may minimize potential for muscle hypertrophy. Second, energy expenditure of ABT is lower than other exercise modes ${ }^{[40]}$, which may be insufficient to induce negative energy balance and thus weight or fat loss. In the present study, $56 \%$ of participants were less than or equal to 1 year post-injury, during which there is a considerable loss in FFM and rise in $\mathrm{FM}^{[56]}$, and it could be that our minimal changes are a result of continued changes in body composition that were not slowed by our intervention. Third, despite wide use of DXA to assess body composition $^{[16,57]}$ and data showing DXA-derived increases in FFM and/or decreases in regional body fat in SCI in response to electrical stimulation training ${ }^{[1,58]}$, its ability to detect small changes in FM or FFM after exercise training is less than magnetic resonance imaging. It is plausible that DXA should only be used in studies when relatively robust changes in energy balance and/or body composition are expected, such as those using high-volume FES-based exercise or manipulation of both exercise and dietary intake to improve health status in this population. Fourth, individual variability in these responses occurred, as FFM declined in persons with complete injury and was unchanged in men and women with incomplete injury. Overall, by itself ABT does not seem to induce significant changes in body composition, especially in persons with acute injury.

Our study had a few limitations. We used a convenience sample composed of individuals who were already completing $\mathrm{ABT}$ at the facility. A non-exercising control group was not recruited, thus we are uncertain if the changes seen in this study are truly due to exercise training. Participants differed in injury duration, 
severity, and completeness that may reduce our ability to gauge the efficacy of ABT, especially in persons with acute SCI who are experiencing changes in body fat and FFM. However, in a previous study ${ }^{[4]}$, regular physical activity improved various physical and psychological outcomes in persons with SCI irrespective of their level or completeness of injury. The Short Form-36 is widely used in populations including SCI to monitor changes in health-related quality of life ${ }^{[29]}$. However, other than its two pain-related items, we did not use it as it was found to be too burdensome on our sample. Although all participants received comprehensive ABT, the make-up and volume of said training varied based on participants' existing function, their progress through training, and, lastly, their ability to pay for training, which was not covered by insurance. This requirement to pay for training may have led to more favorable outcomes related to QOL. The latter factor led to different doses of training performed by each participant. However, there was no relationship between weekly volume of training and the change in \%BF, FFM, or any of the psychological variables. In addition, the increases in PQOL and body satisfaction were evident irrespective of whether participants completed a low or high volume of ABT. These findings suggest that disparate volumes of training had little impact on our results. In addition, FES comprised a small portion of habitual training, which may have led to the non-significant changes in body composition. However, our study is strengthened by a sample size that is greater than those used in most studies examining PQOL. Our sample included persons of varied injury level and injury duration, which allows generalization of our findings to the entire population with SCI rather than one homogeneous group. In addition, we tracked food intake through dietary logs, and data showed minimal changes in energy intake during the study, which gives us greater confidence that observed changes in body composition were not due to variations in dietary patterns.

In conclusion, Six months of ABT slightly improved various indices of quality of life but did not induce changes in body fat or FFM. Pain was also associated with the changes in quality of life and body satisfaction observed in response to training. The changes seen in this study are small. Due to our small and heterogenous sample recruited by convenience, lack of a control group, and non-standardized training regimen, additional work is needed to confirm these data. Future studies should explore the potential for alternative modalities of exercise to enhance quality of life due to its relationship with exercise adherence in SCI.

\section{DECLARATIONS}

\section{Acknowledgments}

The authors thank the participants for their dedication to this study as well as the staff at the rehabilitation facility for overseeing day-to-day training of the subjects.

\section{Authors' contributions}

Conceived the study: Astorino TA, Harness ET

Analyzed the data and wrote the final draft of the manuscript: Astorino TA, which Harness ET reviewed ETH supervised all training sessions; whereas: Harness ET

Supervised all assessments: Astorino TA

\section{Availability of data and materials}

De-identified data could be made available to readers upon request.

\section{Financial support and sponsorship}

National Institutes of Health SC3GM095416-02.

\section{Conflicts of interest}

All authors declared that there are no conflicts of interest. 


\section{Ethical approval and consent to participate}

Not applicable.

\section{Consent for publication}

Not applicable.

\section{Copyright}

(c) The Author(s) 2020.

\section{REFERENCES}

1. Krassioukov A, Claydon VE. The clinical problems in cardiovascular control following spinal cord injury: an overview. Prog Brain Res 2006;152:223-9.

2. Patrick DL, Danis M, Southerland LI, Hong G. Quality of life following intensive care. J Gen Int Med 1988;3:218-23.

3. Hetz SP, Latimer AE, Arbour-Nicitopoulos KP, Martin Ginis KA. Secondary complications and subjective well-being in individuals with chronic spinal cord injury: associations with self-reported adiposity. Spinal Cord 2011;49:266-72.

4. Hicks AL, Martin KA, Ditor DS, Latimer AE, Craven C, et al. Long-term exercise training in persons with spinal cord injury: effects on strength, arm ergometry performance, and psychological well-being. Spinal Cord 2003;41:34-43.

5. Ditor DS, Latimer AE, Martin Ginis KA, Arbour KP, McCartney N, et al. Maintenance of exercise participation in individuals with spinal cord injury: effects on quality of life, stress, and pain. Spinal Cord 2003;41:446-50.

6. Nepomuceno C, Fine PR, Richards JS, Gowens H, Stover SL, et al. Pain in patients with spinal cord injury. Arch Phys Med Rehabil 1979;60:605-9.

7. Ataoğlu E, Tiftik T, Kara M, Tunç H, Ersöz M, et al. Effects of chronic pain on quality of life and depression in patients with spinal cord injury. Spinal Cord 2013;51:23-6.

8. Elliott TR, Frank RG. Depression following spinal cord injury. Arch Phys Med Rehabil 1996;77:816-23.

9. American Psychological Association. Diagnostic and statistical manual of mental disorders. 4th edn. Washington, DC: American Psychological Association; 1994.

10. Moore CD, Craven BC, Thabane L, Laing AC, Frank-Wilson AW, et al. Lower-extremity muscle atrophy and fat infiltration after chronic spinal cord injury. J Musculoskelet Neuronal Interact 2015;15:32-41.

11. Elder CP, Apple DF, Bickel CS, Meyer RA, Dudley GA. Intramuscular fat and glucose tolerance after spinal cord injury--a crosssectional study. Spinal Cord 2004;42:711-6.

12. Fisher JA, McNelis MA, Gorgey AS, Dolbow DR, Loetz LL. Does upper extremity training influence body composition after spinal cord injury? Aging Dis 2015;6:271-81.

13. Gorgey AS, Mather KJ, Gater DR. Central adiposity associations to carbohydrate and lipid metabolism in individuals with complete motor spinal cord injury. Metabolism 2011;60:843-51.

14. Bauman WA, Spungen AM. Coronary heart disease in individuals with spinal cord injury: assessment of risk factors. Spinal Cord 2008;46:466-76.

15. Cragg JJ, Noonan VK, Dvorak M, Krassioukov A, Mancini GB, et al. Spinal cord injury and type 2 diabetes: results from a population health survey. Neurology 2013;81:164-8.

16. Griffin L, Decker MJ, Hwang JY, Wang B, Kitchen K, et al. Functional electrical stimulation cycling improves body composition, metabolic, and neural factors in persons with spinal cord injury. J Electromyogr Kinesiol 2009;19:614-22.

17. Gorgey AS, Shepherd C. Skeletal muscle hypertrophy and decreased intramuscular fat after unilateral resistance training in spinal cord injury: case report. J Spinal Cord Med 2011;33:90-5.

18. McCormack K, Carty A, Coughlan G, Crowe L, Caulfield B. The effects of a neuromuscular electrical stimulation training intervention on physiological measures in a spinal cord injured population. Physiother Ireland 2010;31:30-5.

19. Carty A, McCormack K, Coughlan GF, Crowe L, Caulfield B. Alterations in body composition and spasticity following subtetanic neuromuscular electrical stimulation training in spinal cord injury. J Rehabil Res Dev 2013;50:193-202.

20. Bresnahan JJ, Farkas GJ, Clasey JL, Yates JW, Gater DR. Arm crank ergometry improves cardiovascular disease risk factors and community mobility independent of body composition in high motor complete spinal cord injury. J Spinal Cord Med 2019;42:272-80.

21. Hicks AL, Martin Ginis KA, Pelletier CA, Ditor DS, Foulon B, et al. The effects of exercise training on physical capacity, strength, body composition and functional performance among adults with spinal cord injury: a systematic review. Spinal Cord 2011;49:1103-27.

22. Sadowsky CL, McDonald JW. Activity-based restorative therapies: concepts and applications in spinal cord injury-related neurorehabilitation. Dev Disabil Res Rev 2009;15:112-6.

23. Jones ML, Evans N, Tefertiller C, Backus D, Sweatman M, et al. Activity-based therapy for recovery of walking in individuals with chronic spinal cord injury: results from a randomized clinical trial. Arch Phys Med Rehabil 2014;95:2239-46.e2.

24. Ung RV, Lapointe NP, Rouleau P, Guertin PA. Non-assisted treadmill training does not improve motor recovery and body composition in spinal cord-transected mice. Spinal Cord 2010;48:750-5.

25. Giangregorio L, Craven C, Richards K, Kapadia N, Hitzig SL, et al. A randomized trial of functional electrical stimulation for walking in incomplete spinal cord injury: effects on body composition. J Spinal Cord Med 2012;35:351-60.

26. Rosety-Rodriguez M, Rosety I, Fornieles G, Rosety JM, Elosegui S, et al. A short-term arm-crank exercise program improved testosterone deficiency in adults with chronic spinal cord injury. Int Braz J Urol 2014;40:367-72. 
27. Quel de Oliveira C, Refshauge K, Middleton J, de Jong L, Davis GM. Effects of activity-based therapy interventions on mobility, independence, and quality of life for people with spinal cord injuries: a systematic review and meta-analysis. J Neurotrauma 2017;34:1726-43.

28. Dolbow DR, Gorgey AS, Ketchum JM, Gater DR. Home-based functional electrical stimulation cycling enhances quality of life in individuals with spinal cord injury. Top Spinal Cord Inj Rehabil 2013;19:324-9.

29. Sharif H, Gammage K, Chun S, Ditor D. Effects of FES-ambulation training on locomotor function and health-related quality of life in individuals with spinal cord injury. Top Spinal Cord Inj Rehabil 2014;20:58-69.

30. Sadowsky CL, Hammond ER, Strohl AB, Commean PK, Eby SA, et al. Lower extremity functional electrical stimulation cycling promotes physical and functional recovery in chronic spinal cord injury. J Spinal Cord Med 2013;36:623-31.

31. Reboussin BA, Rejeski WJ, Martin KA, Callahan K, Dunn AL, et al. Correlates of satisfaction with body function and body appearance in middle- and older-age adults: the activity counseling trial (ACT). Psychol Health 2000;15:239-54.

32. Ware JE, Sherbourne CD. The MOS 36-item short form health survey (SF-36). Conceptual framework and item selection. Med Care 1992;30:473-83.

33. Gerhart KK, Johnson RL, Whiteneck GG. Health and psychosocial issues of individuals with incomplete and resolving spinal cord injuries. Paraplegia 1992;30:282-7.

34. Radloff JS. The CES-D scale: a self-report depression scale for research in the general population. Appl Psychol Measure 1977;1:385-401.

35. Miller WC, Anton HA, Townson AF. Measurement properties of the CESD scale among individuals with spinal cord injury. Spinal Cord 2008; 46:287-92

36. Dudley-Javoroski S, Shields RK. Assessment of physical function and secondary complications after complete spinal cord injury. Disabil Rehabil 2006;28:103-10.

37. Heyward VH. Advanced fitness assessment and exercise prescription. 5th Ed. Human Kinetics, Champaign, IL. 2006.

38. Harness ET, Yozbatiran N, Cramer SC. Effects of intense exercise in chronic spinal cord injury. Spinal Cord 2008;46:733-7.

39. Harness ET, Astorino TA. Acute energy cost of multi-modal activity-based therapy in persons with spinal cord injury. J Spinal Cord Med 2011;34:495-500.

40. Collins EG, Gater D, Kiratli J, Butler J, Hanson K, et al. Energy cost of physical activities in persons with spinal cord injury. Med Sci Sports Exerc 2010:42:691-700.

41. Hasnan N, Ektas N, Tanhoffer AI, anhoffer R, Fornusek C, et al. Exercise responses during functional electrical stimulation cycling in individuals with spinal cord injury. Med Sci Sports Exerc 2013;45:1131-8.

42. Evans N, Hartigan C, Kandilakis C, Pharo E, Cleeson I. Acute cardiorespiratory and metabolic responses during exoskeleton-assisted walking overground among persons with chronic spinal cord injury. Top Spinal Cord Inj Rehabil 2015;21:122-32.

43. Astorino TA, Harness ET, Witzke KA. Effect of chronic activity-based therapy on bone mineral density and bone turnover in persons with spinal cord injury. Eur J Appl Physiol 2013;113:3027-37.

44. Rejeski WJ, Ettinger WH, Martin K, Morgan T. Treating disability in knee osteoarthritis with exercise therapy: a central role for selfefficacy and pain. Arthritis Care Res 1998;11:94-101.

45. Padula N, Costa M, Batista A, Gaspar R, Motta C, et al. Long-term effects of an intensive interventional training program based on activities for individuals with spinal cord injury: a pilot study. Physiother Theory Pract 2015;31:568-74.

46. Hausenblas HA, Fallon EA. Exercise and body image: a meta-analysis. Psychol Health 2006;21:33-47.

47. Hienberg LJ, Thompson JK, Matzon JL. Body image dissatisfaction as a motivator for healthy lifestyle change: is some distress beneficial? In: Striegel-Moore RH, Smolak L, editors. Eating disorders: innovative directions in research and practice. Washington, DC: American Psychological Association; 2001. pp. 215-32.

48. Bassett RL, Martin Ginis KA. More than looking good: impact on quality of life moderates the relationship between functional body image and physical activity in men with SCI. Spinal Cord 2009;47:252-6.

49. Semerjian TZ, Montague SM, Dominguez DF, Davidian AM, de Leon RD. Enhancement of quality of life and body satisfaction through the use of adapted exercise devices for individuals with spinal cord injuries. Top Spinal Cord Inj Rehabil 2006;11:95-108.

50. Nash MS, van de Ven I, van Elk N, Johnson BM. Effects of circuit resistance training on fitness attributes and upper-extremity pain in middle-aged men with paraplegia. Arch Phys Med Rehabil 2007;88:70-5.

51. Martin Ginis K, Latimer AE. The effects of single bouts of body-weight supported treadmill training on the feeling states of people with spinal cord injury. Spinal Cord 2007;45:112-5.

52. Alschuler KN, Jensen MP, Sullivan-Singh SJ, Borson S, Smith AE, et al. The association of age, pain, and fatigue with physical functioning and depressive symptoms in persons with spinal cord injury. J Spinal Cord Med 2013;36:483-91.

53. Marcondes BF, Sreepathi S, Markowski J, Nguyen D, Stock SR, et al. Pain severity and mobility one year after spinal cord injury: a multicenter, cross-sectional study. Eur J Phys Rehabil Med 2016;52:626-36.

54. Latimer AE, Martin Ginis K, Hicks AL, McCartney N. An examination of the mechanisms of exercise-induced change in psychological well-being among people with spinal cord injury. J Rehabil Res Dev 2004;41:643-52.

55. Fuhrer MJ, Rintala DH, Hart KA, Clearman R, Young ME. Depressive symptomatology in persons with spinal cord injury who reside in the community. Arch Phys Med Rehabil 1993;74:255-60.

56. Wilmet E, Ismail AA, Heilporn A, Welraeds D, Bergmann P. Longitudinal study of the bone mineral content and of soft tissue composition after spinal cord section. Paraplegia 1995;33:674-7.

57. Sköld C, Lönn L, Harms-Ringdahl K, Hultling C, Levi R, et al. Effects of functional electrical stimulation training for six months on body composition and spasticity in motor complete tetraplegic spinal cord-injured individuals. J Rehabil Med 2002;34:25-32.

58. Gorgey AS, Caudill C, Khalil RE. Effects of once weekly of NMES training on knee extensors fatigue and body composition in a person with spinal cord injury. J Spinal Cord Med 2016;39:99-102. 